\title{
Orbital cellulitis caused by Acinetobacter baumannii: A case report
}

\section{Celulitis orbitaria por Acinetobacter baumannii: Reporte de caso}

\author{
M. Gabriela del Valle González-Cannata*, Alfredo Medina-Zarco, Diana I. González-Hinojosa, \\ Karla J. Aguilera-Ruiz, Martha P. González-Núñez and Dora A. Ochoa-Araujo \\ Hospital Regional Lic. Adolfo López Mateos, Instituto de Seguridad y Servicios Sociales de los Trabajadores del Estado, Mexico City, Mexico
}

\begin{abstract}
Introduction: Orbital cellulitis is an infectious inflammation posterior to the orbital septum, with bacterial infection standing out as the most common cause. Acinetobacter baumannii is an uncommon cause of this pathology. Case Presentation: This is a 54-year-old female who presented progressive right ocular pain and proptosis. She received treatment under hospitalization for a diagnosis of orbital cellulitis in a secondary health center, and after 20 days of hospitalization, she presented a torpid evolution, which resulted in referral to our center, where A. baumannii was detected in cultures. Discussion: The patient's hospitalization prior to admission to our center, associated with a history of diabetes mellitus, are the most important risk factors for this infection. Conclusion: A. baumannii, despite being an infrequent pathogen associated with orbital cellulitis, should not be excluded from the diagnosis considering the severity of the sequelae to which it is associated.
\end{abstract}

Key words: Orbital cellulitis. Acinetobacter baumannii. Nosocomial infection.

\section{Resumen}

Introducción: La celulitis orbitaria es una inflamación infecciosa por detrás del tabique orbitario. Se destaca la infección bacteriana como la causa más común yAcinetobacter baumannii es infrecuente en esta patología. Presentación del caso: Paciente femenina de 54 años de edad, quien presentó dolor ocular derecho progresivo y proptosis. Se dio manejo intrahospitalario por diagnóstico de celulitis orbitaria en una clínica de segundo nivel de oftalmología, y después de 20 días de hospitalización, presentó evolución tórpida, razón por la cual se refirió a nuestro centro, donde se detectó crecimiento de $A$. baumannii. Discusión: La estancia intrahospitalaria de la paciente previa al ingreso en nuestro centro, asociada al antecedente de diabetes mellitus, representan los factores de riesgo más importantes para esta infección. Conclusión: A. baumannii, a pesar de ser un patógeno infrecuente asociado a la celulitis orbitaria, no debe excluirse del diagnóstico debido a la gravedad de las secuelas a las que se asocia.

Palabras clave: Celulitis orbitaria. Acinetobacter baumannii. Infección intrahospitalaria.

Correspondence:

*M. Gabriela del Valle González-Cannata

Av. Universidad, 1321

Col. Axotla

Date of reception: 18-09-2018

Date of acceptance: 26-04-2019

DOI: 10.24875/RMOE.M20000120
Available online: $01-07-2020$ Rev Mex Oftalmol (Eng). 2020;94(4):166-170

www.rmo.com.mx 


\section{Introduction}

Orbital cellulitis is defined as an infectious inflammation of the soft tissues behind the orbital septum, which can be caused by bacteria, viruses, fungi, and protozoa. Bacterial infection is the most common cause, and Acinetobacter baumannii is not a frequent cause of this disorder. Orbital cellulitis is associated with significant complications, so early diagnosis and prompt treatment are of utmost importance for its prognosis.

\section{Clinical case}

A 54-year-old female patient, resident from Veracruz, Mexico, with a history of diabetes mellitus, diagnosed 20 years ago and treated with insulin glargine 40-0-20 IU. Surgical history of breast augmentation, liposuction of the abdomen, and eyebrows, eyelids and lips tattoo. On July 11, 2017 she initiated with progressive right eye pain associated with conjunctival hyperemia and proptosis, followed by an increased volume of periorbital soft tissues with associated headache. She went to the emergency room of a local hospital, where she was admitted and received intravenous treatment with ceftriaxone $1 \mathrm{~g}$ every $12 \mathrm{~h}$, clindamycin $600 \mathrm{mg}$ every $6 \mathrm{~h}$ and topical treatment with ciprofloxacin in the right eye every $6 \mathrm{~h}$ and chloramphenicol every $12 \mathrm{~h}$. She remained hospitalized for 20 days, but later developed phlogosis and ulceration of the right lower eyelid. Therefore, due to the torpid evolution, she was referred to our center.

She was admitted to our service on August 8, 2017. An ophthalmological examination showed a visual acuity of the right eye $(\mathrm{OD})$ of no light perception, visual acuity of the left eye (OS) 20/50 with a visual capacity of $20 / 30$. Limited ductions -4 in all gaze positions. Volume increase in the middle third of the right side of the face, predominantly in the orbital region, with phlogosis, with a 2-mm tissue loss from the lower eyelid border, causing disinsertion of the inner canthus and compromising all the eyelid, with abundant discharge of fetid purulent discharge and a $2.5 \mathrm{~cm}$ long ulcerative lesion in the ipsilateral nasojugal groove with anfractuous bordes, purulent discharge and a necrotic base. Also, with two nodules palpated at the junction of the middle third and the external third of the lower eyelid, firm but not stony, attached to deep planes. Biomicroscopy (OD) showed $360^{\circ}$ chemosis, mixed $360^{\circ}$ conjunctival hyperemia, abundant purulent and serohematic secretion in the cul-de-sac, opaque cornea, with formed anterior chamber, eutrophic iris, reactive pupil, lens with nuclear opacity. Biomicroscopy (OS) without alterations
Table 1. Wound secretion culture and antibiogram

\begin{tabular}{|c|c|}
\hline \multicolumn{2}{|c|}{ Wound culture } \\
\hline \multicolumn{2}{|c|}{ Development of Acinetobacter baumannii } \\
\hline Ampicillin & Resistant \\
\hline Ampicillin/ sulbactam & Sensitive \\
\hline Piperacillin/ tazobactam & Sensitive \\
\hline Cefazolin & Resistant \\
\hline Ceftriaxone & Intermediate \\
\hline Cefepime & Sensitive \\
\hline Aztreonam & Resistant \\
\hline Meropenem & Sensitive \\
\hline Gentamicin & Sensitive \\
\hline Tobramycin & Sensitive \\
\hline Ciprofloxacin & Sensitive \\
\hline Tigecycline & Sensitive \\
\hline Nitrofurantoin & Resistant \\
\hline Trimethoprim/sulfamethoxazole & Sensitive \\
\hline
\end{tabular}

(Fig. 1). Fundoscopy (OD) with pale disc and blurred disc margins, with an excavation of $50 \%$, thinned tortuous vessels and vascular tortuosity and folds in the upper retina. Fundoscopy (OS) normal disc with an excavation of $30 \%$, with applied retina and macula.

Considering the signs and symptoms, we made a clinical diagnosis of right orbital cellulitis (Chandler 2). We did not modify the previous medical treatment and requested a computed tomography of the orbits (Figs. 2 and 3) and blood tests, as well as secretion smears for Gram and cultures. Gram stain reported the presence of polymicrobial agents, cocci and gram-negative bacilli and abundant neutrophils. Bacterial growth occurred at $48 \mathrm{~h}$, reporting $A$. baumannii (Table 1). In view of the microbiological findings, along with the infectious diseases department, the intravenous antimicrobial treatment scheme was modified to piperacillin/tazobactam 4.0/0.5 ml every 6 hours, fluconazole $100 \mathrm{ml}$ every 12 hours and levofloxacin $500 \mathrm{ml}$ every 12 hours.

We decided to debride necrotic tissue, perform surgical cleaning, and take an intraoperative biopsy, which reported mucosa with moderate diffuse chronic inflammatory infiltrate at the expense of lymphocytes and plasma cells, associated with a gigantocellular reaction that extended to deep fat tissue. 


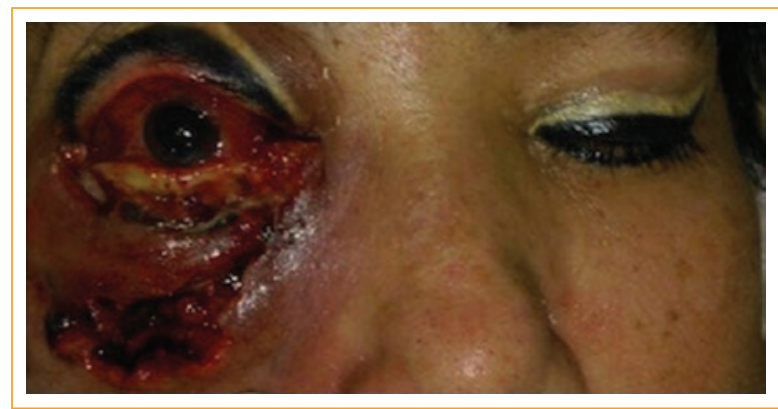

Figure 1. Clinical photograph at admission to our center, where there is evidence of a volume increase in the middle third of the right side of the face, predominantly in the orbital region, with phlogosis, with a 2-mm tissue loss from the lower eyelid border that compromises all the eyelid, with disinsertion of the medial canthal tendon, with fetid purulent discharge and an area of necrosis in the inner canthus. Also, with an ulcerative lesion in the ipsilateral nasojugal groove with anfractuous bordes, purulent discharge and a necrotic base. $360^{\circ}$ hemorrhagic chemosis.

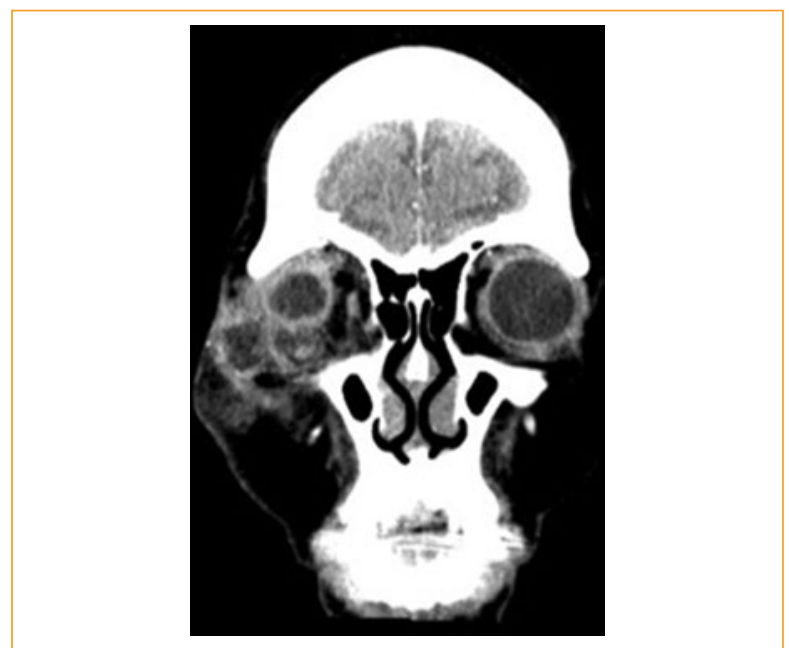

Figure 2. Computed tomography of the orbit, coronal section with and without contrast, with a window for soft tissue. There is evidence of volume increase, predominantly located at inferior and lateral periorbital soft tissues, with septations and nodular appearance, in a number of 3 , heterogeneous, without contrast enhancement, that displace the eyeball upwards. Presence of air in the outer $1 / 3$ of the orbital cavity, as well as in the nasal and inferior portion adjacent to the medial rectus muscle.

Due to the clinical improvement, a surgical reoperation was decided on the fifteenth day of hospitalization to close the tissues of the lower eyelid and to reconstruct the cul-de-sac, with annular conformator placement.

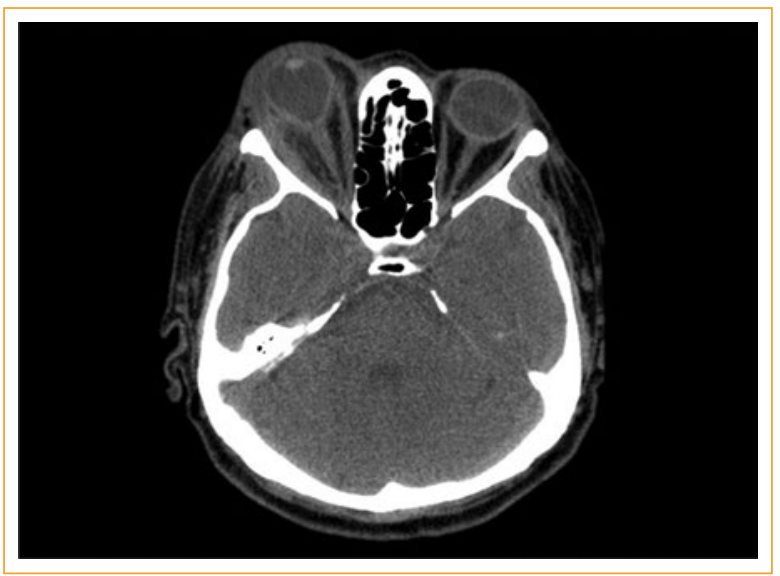

Figure 3. Computed tomography of the orbit, axial section with and without contrast, with a window for soft tissue. Proptosis and diffuse intraconal soft tissue edema that extends towards the orbital vertex, generating narrowing of the optic foramen. With evidence of medial and lateral rectus thickening, deformation of the eyeball due to a mechanical effect on the posterior pole, and rectification of the optic nerve.

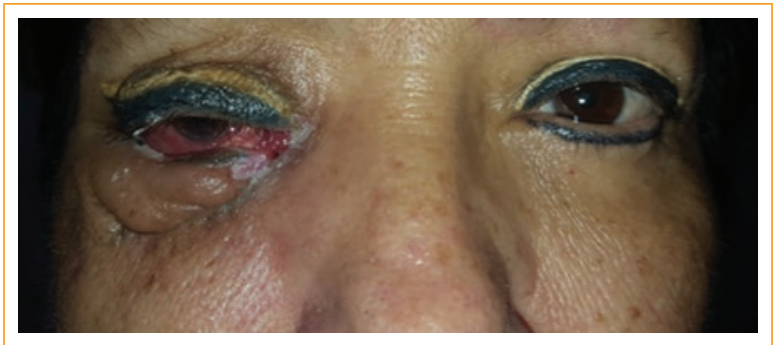

Figure 4. Upon discharge, the patient showed a significant clinical improvement, moderate ptosis and inferior madarosis. Thickened and edematous lower eyelid with scar adhesion in the nasojugal groove, as well as distal displacement of the medial canthal tendon.

The patient was reevaluated by the infectious diseases department, suspending piperacillin/tazobactam and levofloxacin and starting linezolid $600 \mathrm{ml}$ every 12 hours and gentamicin $80 \mathrm{ml}$ every 12 hours. She had a favorable evolution, and was discharged from the hospital with oral medical treatment (linezolid $600 \mathrm{ml}$ every $12 \mathrm{~h}$ for 7 days, Fig. 4).

\section{Discussion}

Orbital cellulitis is a rare condition that can affect all age groups, but is more frequent in the pediatric population, Murphy, et al. reported in 2014 an incidence of 1.6 per 100,000 and 0.1 per 100,000 adults, respectively 1 . 
The most frequent predisposing factor in all age groups is infection that spreads from the paranasal sinuses. This has been shown in studies both in the western world and in the developing world. Specifically, it has been determined that $1.3-5.6 \%$ of sinusitis cases result in orbital cellulitis, and from these, $0.3-5.1 \%$ develop an orbital or subperiosteal abscess ${ }^{2}$. Orbital cellulitis generally comes from the ethmoid sinuses, with a reported frequency of $43 \%{ }^{3}$. It is a rare occurrence after ophthalmic surgery; however, it has been reported after strabismus, eyelid and anterior segment surgery, and after peribulbar injection ${ }^{4}$.

The causative agent in orbital cellulitis can be difficult to identify due to normal flora contaminants, previous use of antibiotics, therapies, and mixed infections. Historically, Haemophilus influenzae type b was one of the most common organisms associated with preseptal and orbital cellulitis in children before the introduction and widespread adoption of the Hib vaccine in 1985 . After the introduction of this vaccine, a marked decrease in cases reported by this microorganism was evidenced. Abscess formation in post-traumatic cases is generally caused by Staphylococcus aureus and Streptococcus pyogenes. In a more recent study examining organisms isolated from orbital abscess cultures and sinus aspirates, Staphylococcus was the most common species (22 positive cultures, $36 \%$ of which were methicillin-resistant $S$. aureus), followed by Streptococcus species (13 positive cultures) $)^{5}$. In immunocompromised patients, mucormycosis and aspergillosis should be considered as the most frequent causative agents. Anaerobic bacteria, including Peptococcus, Peptostreptococcus, and Bacteroides, are less common causes and are associated with infections after human or animal bites. Rare microorganisms include Pseudomonas species, Morganella morganii, Acinetobacter, Bacillus anthracis, Escherichia coli, Actinobacter species, Enterobacter species and several anaerobes such as Propionibacterium acnes, Veillonella species, Prevotella, Porphyromonas, Fusobacterium bacteroides and Clostridium bifermentans ${ }^{6}$.

To the best of our knowledge, this is the first reported case of orbital cellulitis caused by $A$. baumannii.

The Acinetobacter genus comprises a group of gram-negative, non-fermenting coccobacilli, strict aerobes, catalase positive, and oxidase negative. Currently, there are 33 accepted genospecies defined by DNA-DNA hybridization.

Most species of the Acinetobacter genus can be found in water, plants, vegetables, or soil, and can even be found as normal microbiota in the human skin.
A. baumannii is excluded from this group, since it is not a ubiquitous microorganism, does not occur in nature, nor as a colonizer in the community. This pathogen is highly associated with outbreaks of hospital infection due to its great adherence to biomedical equipment, keyboards, curtains and even cell phones of health workers, and it is resistant to the usual low or intermediate level disinfection methods.

In two European studies, Acinetobacter iwoffi was the most predominant species found in the skin of healthy individuals, with carrier rates between 29 and $58 \%$, while other species of Acinetobacter, including Acinetobacter junii, Acinetobacter johnsonii, Acinetobacter radiorresistens and genome sp. 15BJ, were much less frequent ${ }^{7}$. Acinetobacter carrier rates (including genome sp. 13TU) in these studies ranged between 0.5 and $3 \%$, while for the genome sp. 3 , the rates varied between 2 and $6 \%{ }^{8}$. Fecal carriers of $A$. baumannii among outpatients in the UK and the Netherlands reached $0.9 \%$. In a study in Hong Kong, the carrier rates of $A$. baumannii, genome sp. 3 and genome sp. 13TU in the skin of healthy individuals, were 4.32 and $14 \%$, respectively ${ }^{9}$. Little data is available regarding the environmental incidence of $A$. baumannii, genome sp. 3 and genome sp. 13TU, but these species have been found in variable percentages in vegetables, fish, meat and in the soil. All these data indicate that this microorganism has a low prevalence in the community and that its presence in the environment is low.

Acinetobacter spp. is an opportunistic pathogen that has been associated with various types of infections that primarily affect seriously ill patients and/or those admitted to intensive care units (ICUs). Risk factors include recent major surgery, trauma, burns, and external factors, such as prolonged hospital stay, prolonged ICU admission, admission to a service where A. baumannii is endemic, exposure to contaminated medical equipment, mechanical ventilation, use of intravascular devices, urinary catheter, drainage tubes and previous antimicrobial treatments ${ }^{10}$.

The most frequent clinical manifestations in case of nosocomial infection by Acinetobacter are pneumonia associated with mechanical ventilation and primary bacteremia. Other common clinical manifestations are meningitis secondary to external ventricular shunts or ventriculoperitoneal shunts, skin and soft tissue infections, and wound infections in patients with trauma, extensive and severe burns. Endocarditis and endophthalmitis or keratitis (related to contact lens use or after ophthalmic surgery) are exceptional ${ }^{11}$. 
Analyzing the epidemiological characteristics of this pathogen, we consider that this patient had risk factors that compromised her immune system such as diabetes mellitus, making her more susceptible to this kind of infection. She also reported a history of facial aesthetic procedures that, although not considered invasive, are able to inoculate microorganisms. As previously described, the incidence of Acinetobacter as skin flora and its association with soft tissue infections is low but possible. However, it is important to consider the length of hospital stay prior to admission to our center, which we consider the most important risk factor for acquiring this pathogen. We do not have a microbiology report prior to the one performed at our center, and this leads us to propose two hypotheses. Was this the initial infection or the orbital cellulitis was initially caused by another agent and Acinetobacter was acquired during the hospital stay? There are several articles reporting an empirical treatment protocol for orbital cellulitis; however, sampling for Gram, culture and antibiogram is of utmost importance to determine the causative agent and the corresponding specific treatment. In this case, we inititated the antibiotic treatment described in the literature and after 48 hours, considering the microbiology report and the antibiogram, and together with the infectious diseases department, we decided to start the corresponding therapy. A. baumannii infection is associated with serious complications, making timely diagnosis and treatment crucial. The visual prognosis was affected by the retinal ischemic sequelae; however, we achieved a favorable cosmetic rehabilitation that allowed the patient to rejoin her daily activities with little social impact.

\section{Conclusions}

A. baumanii has changed in recent years from being considered a microorganism of little clinical relevance to becoming an increasingly frequent pathogen in hospitalized patients, constituting a true paradigm of nosocomial infections. Despite being an infrequent pathogen associated with orbital cellulitis, it should not be excluded from the diagnosis, especially in patients with one or more risk factors, due to the severity of the sequelae to which it is associated.

\section{Ethical disclosures}

Protection of human and animal subjects. The authors declare that no experiments were performed on humans or animals for this study.

Confidentiality of data. The authors declare that they have followed the protocols of their work center on the publication of patient data.

Right to privacy and informed consent. The authors have obtained the written informed consent of the patients or subjects mentioned in the article. The corresponding author is in possession of this document.

\section{Conflicts of interest}

The authors declare no conflicts of interest.

\section{References}

1. Murphy $\mathrm{C}$, Livingstone I, Foot B, Murgatroyd H, MacEwen CJ. Orbital cellulitis in Scotland: current incidence, aetiology, management and outcomes. Br J Ophthalmol. 2014;98(11):1575-8.

2. Al-Madani MV, Khatatbeh AE, Rawashdeh RZ, Al-Khtoum NF, Shawagfeh NR. The prevalence of orbital complications among children and adults with acute rhinosinusitis. Braz J Otorhinolaryngol. 2013;79(6):716-9.

3. Botting AM, Mclntosh D, Mahadevan M. Paediatric pre- and post-septal peri-orbital infections are different diseases. A retrospective review of 262 cases. Int J Pediatr Otorhinolaryngol. 2008;72(3):377-83.

4. Seongmu L, Michael T. Management of preseptal and orbital cellulitis. Saudi J Ophtalmol. 2011;25:21-9.

5. McKinley H, Steven \& T Yen, Michael \& Miller, Aaron \& G Yen, Kimberly. Microbiology of Pediatric Orbital Cellulitis. American journal of ophthalmology. 2007;144:497-501.

6. Bedwell J, Bauman NM. Management of pediatric orbital cellulitis and abscess. Curr Opin Otolaryngol Head Neck Surg. 2011;19(6):467-73.

7. Morgan DJ, Liang SY, Smith CL, Johnson JK, Harris AD, Furuno JP, et al. Frequent multidrug-resistant Acinetobacter baumannii contamination of gloves, gowns, and hands of healthcare workers. Infect Control Hosp Epidemiol. 2010;31(7):716-21.

8. Seifert H, Dijkshoorn L, Gerner-Smidt P, Pelzer N, Tjernberg I, Vaneechoutte M. Distribution of Acinetobacter species on human skin: comparison of phenotypic and genotypic identification methods. J Clin Microbiol. 1997;35:2819-25.

9. Chu YW, Leung CM, Houang ET, Ng KC, Leung CB, Leung HY, et al. Skin carriage of Acinetobacter s in Hong Kong. J Clin Microbiol. 1999; 37:2962-7.

10. Playford EG, Craig JC, Iredell JR. Carbapenem-resistant Acinetobacter baumanii in intensive care unit patients: risk factors for acquisition, infection and their consequences. J Hosp Infect. 2007;65:204-11.

11. Peleg AY, Seifert H, Paterson DL. Acinetobacter baumanii: Emergence of a Successful Pathogen. Clin Microbiol Rev. 2008;21:538-82. 